\title{
THE HISTORY OF NATIONAL CONSTRUCTIONS OF 1940 (BY THE EXAMPLE OF THE FERGHANA VALLEY)
}

(C) 2020

\author{
Nasritdinov Kabulzhan Makhamadzhanovich, candidate of historical sciences, \\ associate professor of Humanities Department \\ Andijan Branch of Tashkent State Agrarian University (Andijan, Republic of Uzbekistan)
}

\begin{abstract}
Based on scientific, historical and archival sources the author of the paper analyzes the history of developing plans aimed at irrigation of virgin lands in the central part of the Ferghana Valley in the first half of the $20^{\text {th }}$ century by large Russian scientists and specialists. The author also shows a historical picture of the construction of the irrigation facilities of the Ferghana Valley using the high-speed «hashar» folk method in 1940. With the construction of hydraulic structures such as the northern and southern Ferghana canals, a new stage began in the development of irrigated agriculture in the Ferghana Valley, since the water of these hydraulic structures made it possible to irrigate new virgin lands in the central part and foothill areas of the Ferghana Valley. But it should be noted that these large and complex irrigation canals were constructed by the peoples of Uzbekistan mainly with the use of primitive tools such as a hoe, a crow, a shovel, a stretcher and pickaxes. For nearly 80 years, these hydraulic structures have provided agricultural areas with life-giving water. The author of the paper also summarizes the essence of economic measures carried out by the Soviet government on the development of irrigated agriculture in the valley.

Keywords: Ferghana Valley; agriculture; irrigation; riverbed; aqueduct; siphon; extensive development path; bag; «hashar»; hoe; shovel; crow; cubic meter; irrigation; waterworks; land reclamation; foothill; canal; waterworks; construction; district; government; national construction; dam; project; ridge; spillway; hectare; collective farm.
\end{abstract}

$* * *$

УДК 94 (73)

DOI 10.24411/2309-4370-2020-11212

Статья поступила в редакцию 08.11 .2019

\section{СОВЕТСКАЯ ШКОЛЬНАЯ СИСТЕМА В ОЦЕНКАХ ЦРУ НА ПЕРВОНАЧАЛЬНОМ ЭТАПЕ ХОЛОДНОЙ ВОЙНЫ}

(C) 2020

Мамедов Заур Ималверди оглы, аспирант кафедры всеобщей истории, права и методики обучения Самарский государственный социально-педагогический университет (2. Самара, Российская Федераџия)

Аннотащия. Статья посвящена анализу школьной системы СССР Центральным разведывательным управлением. США остро нуждались в информации о своём новом противнике. Ситуация усугублялась закрытостью Советского государства и отсутствием длительной непрерывной традиции разведывательной деятельности американской разведки. Президент и другие органы государственной власти хотели иметь всестороннюю осведомленность о любых процессах и явлениях в мире. Американская разведка должна была быть в состоянии решить эту задачу. В связи с этим первый этап холодной войны для ЦРУ в большей степени основывался на анализе официальных и полуофициальных источников, а также на выработке различных стратегий. Для того чтобы узнать о различных сферах жизни СССР, аналитики извлекали информацию из советской научной литературы, прессы, радио, законодательства и допросов бывших немецких пленных. Бюро национальных оценок во главе с Уильямом Лангером и Шерманом Кентом составляло отчёты о советском военном потенциале, промышленности, сельском хозяйстве, политической системе и многом другом. Советская школьная система рассматривалась специалистами американской разведки в рамках военного и экономического потенциала противника, а также стратегии психологической войны. В статье проанализированы рапорты, касающиеся системы образования в СССР в аспекте школьного обучения, его сильных и слабых сторон. Полученные результаты позволяют сделать вывод о том, что информация о советской школьной системе способствовала формированию внешнеполитического и внутриполитического курса США.

Ключевые слова: ЦРУ; США; СССР; холодная война; американская разведка; школьная система; психологическая война; Советский Союз; система образования; Сталин; Трумэн; Уолтер Беделл Смит; Шерман Кент; Уильям Лангер; Роберт Бирнс; Бюро национальных оценок; просвещение; военный потенциал; образовательная политика.

Хронологические рамки исследования затрагивают начальный этап холодной войны с образования ЦРУ в 1947 году и до смерти Сталина в 1953 году, как смены политического управления в СССР. Комплексных исследований, посвященных аналитической работе Центрального разведывательного управления по Советскому государству в этот период, нет. Есть отдельные работы, в которых изучались различные события, явления, процессы, связанные с CССР, на основе архивных данных американской разведки. К таким относятся статьи Д.В. Суржика, в которых, благодаря рассекреченным документам проекта «Цезарь», автору удалось определить последствия так называемого дела врачей [1, с. 78] и проанализировать ряд других внутриполитических процессов в СССР [2, с. 33]. О внутрипартийной борьбе также пишет С.О. Буранок, в работе которого прослеживается вывод о частичной зависимости молодой разведывательной организации от более опытных ведомств, в частности ФБР [3, с. 61]. А.С. Крым- 
ская проанализировала деятельность Роберта Бирнса в Индианском университете. Будучи деканом исторического факультета и советником ЦРУ, он основал один из крупнейших институтов по изучению России и Советского Союза. Нет никаких сомнений, что его ученики и последователи сделали огромный вклад в понимание СССР со стороны американской разведки [4, с. 206]. А.В. Самохин, проанализировав советский военный потенциал к 1946 году, пришёл к выводу о том, что ЦРУ располагало лишь поверхностной информацией и не знало, несмотря на заявления в рапорте, об основных направлениях военной научноисследовательских и научно-опытных работ. Стоит сказать о допущенной автором фактической ошибке, так как на этот год в США действовала Центральная разведывательная группа, промежуточное звено между УСС и ЦРУ. С выводом об отсутствии у американской разведки в 1940-е годы секретных источников информации по СССР нетрудно согласиться. Но работа выполнена на основе советских документов, без привлечения американских источников [5, с. 5]. Социальные стороны Советского государства были затронуты в статье Й. Левента о советской молодёжи в оценках ЦРУ в период с 1947 по 1958 г. Автор всесторонне рассматривает в основном студентов как объект анализа американской разведки. Оcновной вывод работы гласит о превосходстве морального авторитета СССР над США на международной арене. Советская молодежь как целевая группа в психологической войне ЦРУ не рассматривается [6, с. 144]. Остальные работы по анализу ЦРУ Советского государства либо затрагивают более поздний исторический период, либо касаются СССР косвенно.

Переписка руководителей ЦРУ и Комитета по планированию семьи подтверждает тот факт, что советские дети в целом интересовали американскую разведку. Американцев волновала послевоенная демографическая стабилизация в СССР. Данные по этому вопросу расценивались в рамках стратегического увеличения военного потенциала и подготовки к войне. По мнению американской разведки, «Сталин готовит пушечное мясо, как ранее это делали Гитлер и Муссолини». Для предотвращения быстрого увеличения населения, как в СССР, так и в целом в социалистическом блоке, мы обнаруживаем в письме рекомендации по распространению контрацептивов и брошюрах по их применению [7, р. 2]. В одном из рапортов ЦРУ мы находим проблемный вопрос, ответ на который, по мнению аналитиков американской разведки, кроется, в том числе, в особенностях советской школьной системы. Вопрос звучит следующим образом: «Как Советы смогли так быстро развить свою атомную программу и создать Миг-15?» Эта базовая установка даёт нам возможность понять, что военные аспекты даже советской школы волновали ЦРУ больше всего. Второй директор ведомства генерал Уолтер Беделл Смит формировал свои аналитические отделы, затачивая их деятельность под военно-технологическую проблематику [8, p. 11].

Увеличение количества комсомольцев и обучающихся в партийных школах свидетельствовали ЦРУ об эффективной воспитательной работе в школе [9, p. 3]. Одним из положительных моментов образования СССР является тесная связь школы с родителями. Советские органы власти, несущие полную ответственность за проведение образовательной поли- тики, пытаются работать в тесном контакте с родителями. Причём, по мнению американских аналитиков, это удаётся без особой идеологической обработки семьи учащихся. В то же время индокринация самих учащихся происходит путём создания первичных комсомольских организаций и политических курсов. Американские аналитики примечают тот факт, что ученики, не являющиеся членами комсомола, не подвергались прямому давлению на вступление. Послевоенное восстановление школ происходило с помощью неоплачиваемого энтузиазма родителей и старшеклассников. ЦРУ отмечало хоть и медленную, но всё же прогрессию в научном отношении. Постоянное переиздание советских учебников и внедрение в их содержании самых передовых знаний в области химии, ботаники, зоологии, физиологии на принципах дарвинизма и учения Мичурина подтверждали этот вывод [10, p. 3].

При всех проблемах советской системы образования ЦРУ фиксировало пропорциональное увеличение образовательных расходов вместе с затратами на оборону. Из этого делался поспешный вывод о том, что образование в СССР имело под собой в первую очередь военные цели [11, р. 2]. Данное убеждение подтверждали еженедельные двухчасовые курсы военной подготовки в старших классах, омолаживание и примерное гендерное равенство педагогического состава. О военной подготовке ЦРУ имело довольно подробное представление. Восьмиклассники практиковались с маленькими калибровочными винтовками и проходили инструктаж по разборке стандартной стрелковой винтовки. В девятом классе большое внимание уделялось стрельбе. По мнению американских специалистов, это сокращало время для базового военного обучения и имело под собой цель психологической подготовки к военной службе. По результату подрастало большое количество мальчиков, гордящихся приближающимся призывом. Отмечалось, что выбритые головы мальчиков вселяли мужественность среди молодых людей.

Патриотическое воспитание на уроках истории совмещало в себе идеи русского национализма и коммунизма. Великие исторические события плавно включались в идеологические установки и становились неотъемлемой частью построения коммунизма. Подвиги царских генералов инкорпорировались в официальную идеологию. Игнорировался факт защиты ими царского режима. В биографиях великих личностей искалось рабоче-крестьянское происхождение. Анализируя школьные предметы, мы можем заметить, что количественно ЦРУ уделяло внимание в большей степени истории, литературе и географии. Эти предметы значатся в отчётах американской разведки как политические и паравоенные. Американская разведка подсчитывала в процентном соотношении 45\% отводимого графика языку, истории, географии и искусствам, в рамках которых осуществляется идеологическая обработка. Математике, техническим и естественным наукам было посвящено $35 \%$. На этих предметах закладывалось понимание окружающей среды и экономики. По $10 \%$ отводилось физическому воспитанию и иностранному языку. География способствовала улучшению в стране кадров по картографии и геодезии. Зная об американских самолётах-шпионах, которые «работали» над СССР с конца 1950-х годов, и о впечатляющих ЦРУ достижениях в советском самолётостроении, 
эти знания интересовали американскую разведку как нарастающий потенциал для стратегической авиаразведки в будущем.

Не упуская военный контекст, ЦРУ идентифицировало формирование образа врага в советской школе в лице американского истеблишмента. В то же время фиксировалась идея об угнетённости народа США, который в будущем обречён на освобождение. Старшеклассники, как и в целом молодёжь, не боялись новой мировой войны в отличие от старшего поколения. При этом военный долг в школах обсуждался исключительно с точки зрения оборонительной войны [12, p. 7-11].

Среди положительных аспектов советской системы ЦРУ отмечало относительно дешёвые учебники и школьные принадлежности. Отмечались декларативные конституционные основы СССР о культурной свободе в республиках, гарантирующей равные права. Американские специалисты в данном аспекте примечали значительное превосходство над царской Россией. В связи с этим в комсомол вступали успевающие ученики, подавляющее большинство из которых делало это из идеалистических побуждений. ЦРУ отмечало, что советские школьники не искали особого фаворитизма, в котором особо и не нуждались. На основе допросов детей бывших немецких пленных в городе Осташков ЦРУ также фиксировало отсутствие распространения антисемитских взглядов среди школьников и открытого порицания религии. А вот милитаристские тенденции в школьной системе американские аналитики подтверждали распространённым явлением директоров - бывших боевых офицеров Красной армии и участников войны [13, р. 12-14].

В рамках военного потенциала ЦРУ рассматривало физическую подготовку советских школьников. Отвергая в большинстве документов экономические цели советской системы образования, в одном из рапортов аналитики американской разведки делают вывод, что, помимо подготовки будущих солдат, целью физического воспитания также является подготовка здоровых рабочих. ЦРУ было известно об отличительных значках «Готов к труду и обороне». Усиливал вывод о военных целях и тот факт, что испытания для ГТО контролировались партийными функционерами и военными комендантами. Не уходя от этих предположений, американские аналитики отмечали высокие успехи советских спортсменов в футболе, волейболе, гимнастике, баскетболе, тяжёлой атлетике, коньках. Наличие в этом списке шахмат на высоком третьем месте вряд ли основывалось на непобедимости шестого чемпиона мира Михаила Ботвинника и большом количестве союзных турниров. Судя по всему, ЦРУ также отмечало высокий интеллектуальный уровень советских молодых людей, которые в перспективе сделают СССР ещё более опасным противником. Это подтверждает пассаж в рапорте о том, что каждый вид спорта ориентирован на военную подготовку [14, p. 2].

Оценивая в негативном ключе важнейшие цели коммунистического режима в СССР, аналитики американской разведки видели в создании образовательных учреждений способ продвижения тоталитарных планов Сталина. Пронизывающие все уровни и типы советского образования политическая реабилитация и практическая профессиональная подготовка обеспечивали высокую степень централизо- ванного управления образовательной политикой. В связи с этим ЦРУ отмечало эти антидемократические и антилиберальные тенденции как усиление военного потенциала и неуязвимость советского населения перед вражеской пропагандой.

В своём рапорте американская разведка фиксировала превосходство советского народного образования над сильно ограниченным царским образованием. В сравнении с американским курсом обучения более сложное советское семилетнее образование демонстрировало высокие темпы индустриализации. Неуспевающие ученики старших классов пополняли трудовые резервы, оценивающиеся в 3,5 млн человек. В результате такой политики остронуждающиеся отрасли промышленности получали полуквалифицированных работников без ущерба для достижения образовательных задач и социализации большого количества молодых людей. Эти показатели совершенствуются путём обучения в младших классах в прикладном промышленном ключе. Политехничность советского школьного образования способствовала формированию основ для широкого понимания всего производственного процесса в раннем возрасте. Таким образом, в документе «Цели достижения образования в СССР» мы видим фиксацию позитивных экономических последствий. Безусловно, данные выводы ЦРУ побуждали американское руководство реформировать собственную систему образования. Президент Трумэн, как представитель демократической партии, проводил конверсию экономики, стимулируя не только покупательский спрос, но и обогащая американские социальные институты. Американские специалисты фиксировали статус учителей как авторитетный в школе, в обществе и в местных органах власти. Педагог являлся архитектором и проводником позитивных идей человечества. Оклад учителей ЦРУ сопоставляло с заработными платами квалифицированных рабочих. Фиксировались привилегии работников системы образования в виде жилищных субсидий и прав на сниженные цены в государственных магазинах.

Из этого же рапорта мы узнаём о методологии изучения советской школьной системы. Оценка достижений имеет два типа: количественный и качественный. Первый тип подразумевает под собой подсчёт и выведение пропорции общего количества учеников с выпускниками. Качественное измерение в этой сфере ЦРУ представляло в сравнении результатов с объявленными целями. При этом качественная оценка основывалась в этих рапортах на косвенных и более тонких доказательствах, способствующих определить эффективность выпускников. Погрешность в данном вопросе оценивалась американской разведкой в 1-2 процента. Цели и задачи образования ЦРУ брало из указов и нормативных актов. Описание «коммунистической морали» и содержание методики преподавания базировалось на опубликованной научной литературе. Анализ недостатков выявлялся на заявлениях в советской прессе. Авторы рапорта сообщают о высокой степени правдивости этих заявлениях, но признают периодическую трудность в определении общего или регионального характера слабостей. Не исключается в данном контексте и тенденциозность официальной прессы. Таким образом, мы видим критический подход к официальным советским источникам [15, p. 15-18]. К тому же прослеживающееся в большинстве документов противо- 
поставление и примечание сильных и слабых сторон советской школьной системы приводит нас к выводу о том, что в качестве основного метода изучения Бюро национальных оценок ЦРУ предпочитало метод бинарных оппозиций. Этот вывод подтверждают и другие документы по советской промышленности, сельскому хозяйству и другому.

В этом ключе американская разведка идентифицировала уязвимые места советской школьной системы. Среди них можно выделить высокую неуспеваемость и плохую посещаемость. Аналитики ЦРУ на основе заявлений Совета Министра Узбекистана связывали этот процесс с задействованием учеников на сельскохозяйственных работах. В большом количестве документов фиксировалась нехватка учителей, школ, кабинетов и учебников. Наличие вторых и третьих смен создавало большую нагрузку на школьную систему и качество обучаемости. ЦРУ прогнозировало нарастание навязывания русского языка в республиканских школах [10, р. 2].

Некоторые стороны взаимоотношений внутри школы американская разведка считала негативными. В частности, в рапортах приводились примеры подслушивания разговоров и происходящего на уроках со стороны заведующих учебной и воспитательной работы. К этому же фактору относили невозможность со стороны учащихся задавать вопросы во время урока вне очереди. С другой стороны, по мнению ЦРУ, средний советский ученик не имел опыта, который мог бы заставить его подумать об альтернативности образовательного материала.

Не подтверждая фактами, американские специалисты в кавычках приводили список фраз, способствующих дискредитации советской школьной системы или интерпретации их в данном ключе. Судя по всему, данный перечень должен был быть рекомендован Комитету психологической стратегии, который интегрировал бы их в рамках психологической войны в средства массовой информации. Нами были обнаружены следующие потенциальные заголовки: «Коммунистические преступления против целостности образования, науки и культуры», «Изменения в текстах истории советской средней школы», «Политбюро не хочет прекращать сегрегацию в школах», «Один из двадцати пяти человек получает десятилетнее советское образование», «Образование в СССР продолжает отставать», «Четыре года обучения максимальным для большинства советских учеников», «Консервативные тенденции советского образования» $[16$, р. 2]. Можно заметить, что данные цитаты слабо поддаются проверке, но очень легко смогли бы применяться в западной пропаганде. Вывод об их хотя бы частичной фальсификации напрашивается сам по себе.

Разумеется, ЦРУ связывало ряд негативных сторон советской школы с последствиями войны. В результате этого намечались признаки ухудшения качества подготовки преподавательского состава, которые обучались по ускоренному курсу. Большое количество учителей строго придерживалось учебного материала из учебника, никогда не противореча ему и не вводя никаких собственных идей. С одной стороны, это воспринималось американской разведкой как хорошая политическая обработка педагогических работников, а с другой - как слабое владение передовыми методиками и приёмами. Вместо этого в школе практиковались ставшие уже консервативным явлением «брошенные» цитаты Маркса, Энгельса, Ленина и Сталина. Также в данном ключе в прессе искались меры дисциплинарных мер по отношению к учителю. ЦРУ не обнаруживало нарастания стресса в образовательной среде в связи с вышеперечисленными тезисами. Советские школьники, по мнению американских аналитиков, не были знакомы с реалиями взрослой жизни, как, в свою очередь, те - с реалиями жизни в свободных странах [13, р. 17]. При этом отмечалась значительная доля недисциплинированных учеников. В советской прессе ЦРУ находило жалобы со стороны вузов, возлагающих ответственность и обязанность в решении этой проблемы на средние школы [17, p. 2].

Основываясь на компиляции жалоб из советских периодических изданий, американские аналитики приводили в качестве статистики от 12 до $15 \%$ учеников-второгодников ежегодно. Это явление, в свою очередь, создавало утечку образовательных ресурсов и чрезмерную концентрацию усилий, особенно в младших классах. В результате на учителей оказывалось давление, которое отвлекало внимание от средних и сильных учеников. Примечательна причина, которую называют авторы рапорта, - отсутствие интереса со стороны учеников и низкое качество образовательного предложения. А уж нанятые на сельскохозяйственные или промышленные работы старшеклассники теряли стимул к завершению обучения в школе. В этом ключе ЦРУ видело также нереализованность конституционных основ и поставленных образовательных задач, что, в свою очередь, создавало ещё один повод для негативной пропаганды со стороны США [15, p. 19-21].

В этом же ключе ЦРУ старалось диагностировать социально-экономическую поляризацию, влиявшую на поступление в вузы $[18$, p. 2]. Поступление в химические вузы абитуриентов из бывших пионеров приветствовалось, но всё же приоритет отдавался успешно сданным экзаменам [19, р. 3]. Абитуриент, плохо учившийся, но являющийся комсомольцем, имел возможность до вступительных испытаний устроиться помощником к вузовскому преподавателю и лучше подготовиться [20, р. 5]. Анализировались приоритеты среди советских школьников при поступлении в техникумы. В порядке наибольшей значимости для молодых людей американская разведка располагала технические, сельскохозяйственные и педагогические средние профессиональные учебные учреждения [21, p. 2]. Особым статусов среди абитуриентов пользовались медицинские институты, в которых можно было отучиться по специальностям: педиатрия, гигиена, терапия, фармацевтика, стоматология и другие [22, р. 1]. На основе информации по архитектурным институтам ЦРУ делало выводы о том, что дети интеллигенции и советской аристократии (так авторы рапорта называли представителей партийных и государственных органов) заранее имели больше шансов для карьерного роста $[23$, p. 3]. На основе журнала «Московская Патриархия» американская разведка узнавала об особенностях поступления в православные семинарии и академии. В одном из таких рапортов мы обнаруживаем полный список требований к абитуриентам. Хотя такого вывода в документе нет, но, интерпретируя информацию в нём, мы можем предположить, что аме- 
риканская разведка пыталась найти признаки создания трудностей для поступлений в религиозные учебные заведения в СССР. Возможно, упоминание целых девяти требований в документе является скрупулёзной работой авторов рапорта и добросовестностью приведения всей разведывательной информации [24, p. 2]. Таким образом, мы можем предположить, что Комитет психологической стратегии всячески искал перспективы расслоения советского общества по образовательному признаку в будущем.

Представление о милитаризированной школьной системе СССР было не только обоснованием для увеличения военных расходов США. Образ Советского государства как агрессора должен был поспособствовать разработке и применению стратегии психологической войны [25, с. 24]. Разведывательные данные по советской школе использовались в процессе информационного воздействия на население США, Западной Европы, а впоследствии и страны социалистического блока. Дискредитация коммунистических идей, экономическая отсталость СССР, неудовлетворённость социально-экономическим и политическим положением - те факторы, которые культивировались в прессе, радио, искусстве. ЦРУ воспроизводило в культурном пространстве двойное нагнетание. С одной стороны, у населения западного мира должно было сформироваться мнение о негативных последствиях левых идей и угрозе собственного благополучия; с другой стороны, в процессе ослабления железного занавеса у граждан Восточной Европы и СССР зрело осознание собственной отсталости и привлекательности западного образа жизни. Можно сказать, что американская разведка осуществляла «футуроцид», при котором любой неугодный для США образ будущего должен был быть ликвидирован.

\section{Список литературы:}

1. Суржик Д.В. Перевод рассекреченного доклада «Отмена "дела врачей" и его ближайшие следствия» проекта «Цезарь» ЦРУ США // Новые источники и источниковедение. 2017. № 2 (7) - 3 (8). С. 73-79.

2. Суржик Д.В. «Цезарь-5. Удаление Мельникова на Украине». Рассекреченный доклад ЦРУ США // Новые источники и источниковедение. 2018. № 3 (12). C. 29-34.

3. Буранок С.О. Дело Л.П. Берии в оценках ЦРУ, 1953-1954 гг. // Новые исторические перспективы. 2016. № 4. C. 59-62.

4. Крымская А.С. Роберт Бирнс на посту руководителя Института русских и восточноевропейских исследований Индианского университета // Петербургский исторический журнал. 2017. № 1. С. 204-215.

5. Самохин А.В. Советский военный потенциал по оценкам ЦРУ до 1946 года // Новые исторические перспективы. 2016. № 2 (3). С. 5-16.

6. Левент Й. Документы ЦРУ 1947-1958 гг. о послевоенной советской молодежи // Молодой исследователь Дона. 2019. № 4 (19). С. 141-144.

7. Letter to Mr. B.I. Rutledge from Roscoe H. Hillenkoetter // Central Intelligence Agency Library, Langley (Virginia). CIA-RDP80R01731R003100150077-2. 6 May 1947. 4 p.

8. Soviet education in geodesy and cartography. Report // Central Intelligence Agency Library, Langley (Virginia). CIA-RDP79-00202A000100020001-4, 27 January $1954.116 \mathrm{p}$.
9. Review of the 1950-1951 school year in the USSR party education system. Report // Central Intelligence Agency Library, Langley (Virginia), CIA-RDP8000809A000700050205-7. 19 March 1952. 17 p.

10. Newspapers as indicated, 1949-50 school year in USSR. Report // Central Intelligence Agency Library, Langley (Virginia), CIA-RDP80-00809A0006002702874. 2 December 1949. 9 p.

11. Financing capital investment as indicated. Report // Central Intelligence Agency Library, Langley (Virginia). CIA-RDP80-00809A000700070502-5, 15 August $1952.5 \mathrm{p}$.

12. Secondary education at Gorodomlya and Ostashkov. Report // Central Intelligence Agency Library, Langley (Virginia), CIA-RDP80-00810A0011003200013, 8 May 1952. 13 p.

13. Goals and attainments of education in the USSR. Report // Central Intelligence Agency Library, Langley (Virginia), CIA-RDP81-01030R000100270004-7, 4 May 1952. $35 \mathrm{p}$.

14. Soviet curriculum for physical education teacher // Central Intelligence Agency Library, Langley (Virginia), CIA-RDP82-00047R000300160005-5, 21 July 1953. 2 p.

15. Goals and attainments of education in the USSR. Report // Central Intelligence Agency Library, Langley (Virginia), DOC_0000233854, 4 May 1951. 43 p.

16. Overlap by ORR on OIR responsibility for research on Soviet education. Report // Central Intelligence Agency Library, Langley (Virginia), CIARDP80R01731R003500060008-4, 16 May 1952. 6 p.

17. Factors affecting the status of technical education in the USSR. Report // Central Intelligence Agency Library, Langley (Virginia), CIA-RDP8200047R000200200003-3, 5 December 1952. 2 p.

18. Factors affecting the status of technical education in the USSR. Report // Central Intelligence Agency Library, Langley (Virginia), CIA-RDP8000809A000600030239-4, 5 December 1952. 2 p.

19. Soviet higher education in inorganic chemistry and electro-physics. Report // Central Intelligence Agency Library, Langley (Virginia), CIA-RDP8000809A000600030625-5, 8 April 1953. 4 p.

20. Secondary education at Gorodomlya and Ostashkov. Report // Central Intelligence Agency Library, Langley (Virginia), CIA-RDP80-00810A001100320001-3, 8 May 1953. 13 p.

21. Soviet higher education in inorganic chemistry in the USSR. Report // Central Intelligence Agency Library, Langley (Virginia), CIA-RDP80-00809A000600050101-4, 3 January $1953.18 \mathrm{p}$.

22. Scientific - medicine, education institutes. Report // Central Intelligence Agency Library, Langley (Virginia), CIA-RDP80-00809A000600360086-7, 9 November $1950.8 \mathrm{p}$.

23. Education of engineers in the USSR. Report // Central Intelligence Agency Library, Langley (Virginia), CIA-RDP82-00047R000300520006-4, 28 October 1953. 3 p.

24. Political, sociological - education of clergy. Report // Central Intelligence Agency Library, Langley (Virginia), CIA-RDP80-00809A000700030395-9, 11 December $1951.3 \mathrm{p}$.

25. Ивашев А.А. Американская стратегия психологической войны против СССР на начальном этапе холодной войны (1946-1953): автореф. дис. ... канд. ист. наук. Краснодар, 2007. 26 с. 


\title{
THE SOVIET SCHOOL SYSTEM IN CENTRAL INTELLIGENCE AGENCY ESTIMATES AT THE INITIAL STAGE OF THE COLD WAR
}

(C) 2020

Mamedov Zaur Imalverdi oglu, postgraduate student of World History, Law and Methods of Teaching Department Samara State University of Social Sciences and Education (Samara, Russian Federation)

Abstract. The paper is devoted to the analysis by the Central Intelligence Agency of the USSR school system. The US was in dire need of information about its new adversary. The situation was aggravated by the closed nature of the Soviet state and the absence of a long continuous tradition of intelligence activities of American intelligence. The president and other government bodies wanted to have comprehensive knowledge of any processes and phenomena in the world. US intelligence should have been able to solve this problem. In this regard, the first stage of the Cold War for the CIA was largely due to an analysis of official and semi-official sources, as well as the development of various strategies. In order to find out about various areas of the life in the USSR, analysts extracted information from Soviet scientific literature, press, radio, legislation and interrogations of former German prisoners. The National Assessment Bureau, led by William Langer and Sherman Kent, compiled reports on Soviet military capabilities, industry, agriculture, the political system, etc. The Soviet school system was considered by American intelligence specialists in the framework of the military and economic potential of the enemy, as well as the strategy of psychological warfare. The paper analyzes the reports concerning the educational system in the USSR in the aspect of school education, its strengths and weaknesses. The results allow us to conclude that the information about the Soviet school system contributed to the formation of the foreign policy and domestic policy of the United States.

Keywords: Central Intelligence Agency; USA; USSR; Cold War; American intelligence; school system; psychological warfare; Soviet Union; educational system; Stalin; Truman; Walter Bedell Smith; Sherman Kent; William Langer; Robert Byrnes; Bureau of National Assessments; education; military potential; educational policy.

\section{РАЗВИТИЕ МЕДИЦИНЫ КАК ФАКТОР «ЭПИДЕМИЧЕСКОГО ПЕРЕХОДА» У ГОРОДСКОГО НАСЕЛЕНИЯ СРЕДНЕГО ПОВОЛЖЬЯ}

(C) 2020

\author{
Румянцева Мария Александровна, кандидат исторических наук, доцент, \\ научный сотрудник кафедры «Экономика и менеджмент» \\ Филиал Самарского государственного технического университета в г. Новокуйбышевске \\ (2. Новокуйбышевск, Самарская область, Российская Федераџия)
}

\begin{abstract}
Аннотация. В представленной статье автор рассматривает развитие медицины в двадцатом веке как фактор, который существенным образом изменил заболеваемость, а с ней и смертность населения Среднего Поволжья. Появление пенициллина и стрептомицина, массовые прививочные кампании и пропаганда здорового труда и быта, борьба с переносчиками заболеваний и успехи медицинской науки, рост числа врачей и больничных коек на душу населения и доступная бесплатная медицинская помощь - все это привело к значительному уменьшению числа опасных эпидемий в стране. Не обошли данные процессы и городское население Среднего Поволжья. До единичных случаев снижается заболеваемость полиомиелитом и малярией, сибирской язвой и туляремией, чумой и дифтерией, натуральной оспой и холерой, в разы уменьшилась заболеваемость тифом и дизентерией, что привело к сдвигу в структуре смертности населения региона, экзогенные факторы смертности уступают место эндогенным. Смещение заболеваемости в сторону новообразований и сердечно-сосудистых заболеваний - это тоже тенденция времени. И именно произошедший во второй половине XX века процесс «эпидемического перехода» как части перехода демографического определяет современные тенденции заболеваемости и смертности населения региона.

Ключевые слова: эпидемический переход; инфекционные заболевания; смертность; заболеваемость; экзогенные факторы; эндогенные факторы; квазиэкзогенные факторы; городское население; Среднее Поволжье; развитие медицины; советская медицина; успехи медицинской науки; сердечно-сосудистые заболевания; демографический переход; заболеваемость новообразованиями; развитие медицины в России.
\end{abstract}

«Эпидемический переход» - важный этап в эволюции демографического развития человечества. Факторы, его составляющие, по-прежнему являются актуальнейшей проблемой демографической истории. В данной работе нами будет рассмотрен такой немаловажный фактор «эпидемического перехода», как развитие медицины. Под «эпидемическим переходом» мы понимаем изменения в структуре заболеваемости и смертности населения, произошедшие в результате резкого снижения смертности от экзогенных факторов (эпидемии и голод), и относительного роста смертности от эндогенных факторов (заболеваний кровеносной системы, злокачественных новообразований).

Может показаться, что об успехах советской медицины уже многое сказано (взять хотя бы выходившие регулярно работы по истории советского здравоохранения) [1-3], но работ, связывающих 